\title{
DENTAL SHOWCASE
}

\section{Super loupes}

Keeler will be showing its range of dental loupes and accessories at the exhibiton this year on stand M02. Among the products on display will be the SL Super$\mathrm{Vu}$ and XL Advantage loupe ranges.

SL SuperVu uses a Galilean optical system which delivers between 2.0x and 3.0x magnification and provides a wide field of view over the whole treatment area with a large depth of field.

The XL Advantage range uses a primatic optical system offering higher magnification levels (between $3.5 \mathrm{x}$ to $5.5 \mathrm{x}$ ) with exceptional clarity, ideal for more exacting procedures.

There will also be a new loupe hinge on display which allows a greater level of adjustment, ensuring users can obtain optimum posture. In addition to loupes and loupe accessories Keeler will be showing its fibre optic lighting systems.

Designed for direct attachment to loupes they provide 200 watts of bright shadow-free illumination directly on the treatment area.

Reader response number 65

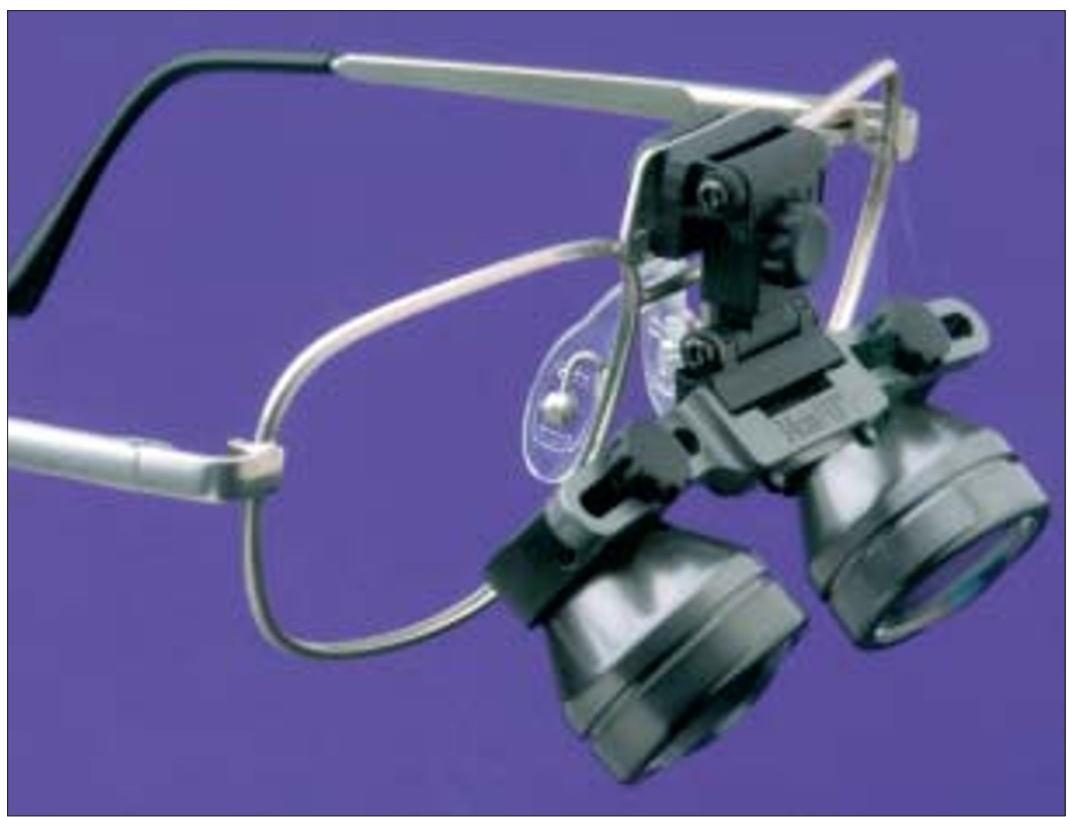

\section{Colgate show new additions}

The Colgate stand will feature dedicated areas for the new Colgate Sensitive toothpaste and new Colgate FluoriGard Alcohol Free rinse.

In addition, there will be fantastic special offers and the chance to win some prizes. The winner of the Colgate Oral Health Month Practice Competition will also be announced H09.

Reader response number 66

\section{Colgate}

\section{Making a change}

Dentists considering a move from NHS to the private sector or looking for a private patient scheme may want to visit the Practice Plan stand at D03.

The company claims it already successfully provided over 750 dental practices throughout the UK with their own, individual, private patient schemes.

It can develop a payment scheme for a practice which protects the hourly rate whilst retaining the practice's identity and offering patients a greater choice of treatments.

Reader response number 68

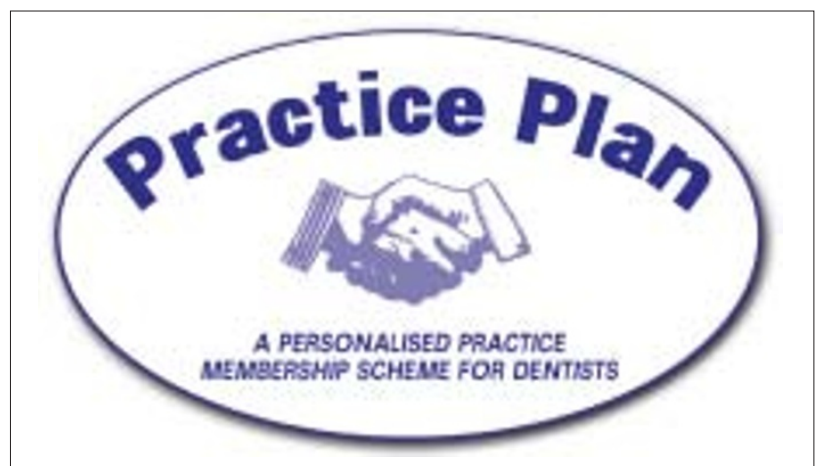

\section{Sitting pretty}

Visitors to Stand J04 will have the opportunity to sit on a Support Stool, a fully adjustable stool designed to hold the dentist in the correct anatomical posture. The operator's pelvis is tilted forward whilst allowing the spine to hold its natural 'S' shape at all times, even when leaning forward.

To help reduce the risk of back, shoulder and neck pain even more, Support Stool offer a range of optional accessories. These include 'Relax' and 'Hydro' armrests, which allow flexibility of movement for the hand whilst supporting the arm.

They will also be demonstrating the VersaFile Healthcare Storage System, available as either mobile cabinets or as a static system.

Reader response number 67

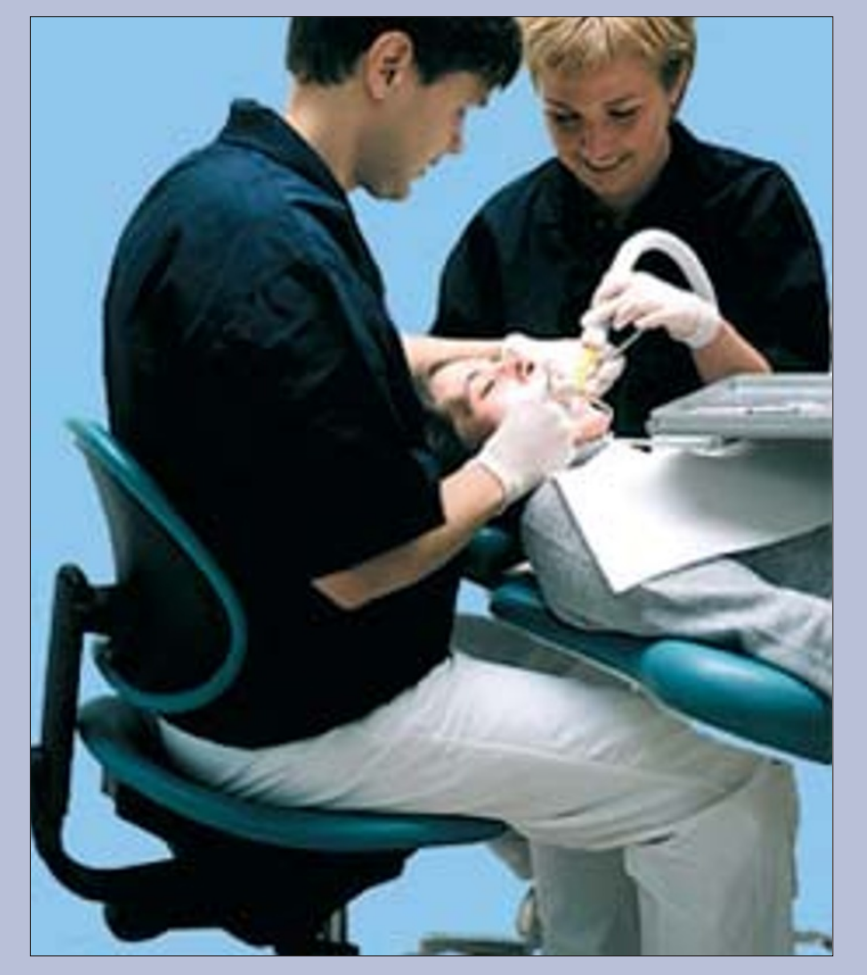

